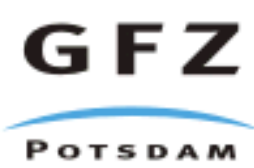

Originally published as:

Korte, M., Mandea, M., Kotzé, P., Nahayo, E., Pretorius, B. (2007): Improved observations at the southern African geomagnetic repeat station network. - South African Journal of Geology, 110, 2-3, 175-186,

DOI: 10.2113/gssajg.110.2-3.175. 


\title{
Improved observations at the southern African geomagnetic repeat station network
}

\author{
M. Korte ${ }^{1}$, M. Mandea ${ }^{1}$, P. Kotzé ${ }^{2}$, E. Nahayo ${ }^{2}$ and B. Pretorius ${ }^{2}$ \\ ${ }^{1}$ GeoForschungsZentrum Potsdam, Telegrafenberg, 14473 Potsdam, Germany, e-mail \\ monika@gfz-potsdam.de (M. Korte) \\ mioara@gfz-potsdam.de (M. Mandea) \\ ${ }^{2}$ Hermanus Magnetic Observatory, PO Box 32, Hermanus, 7200, South Africa, e-mail \\ pkotze@hmo.ac.zo (P. Kotzé) \\ enahayo@hmo.ac.zo (E.Nahayo) \\ bpretorius@hmo.ac.zo (B. Pretorius)
}

short running title: Southern African geomagnetic repeat station survey

(Final draft of paper: Korte, M., M. Mandea, P. Kotzé, E. Nahayo and B. Pretorius (2007): Improved observations at the southern African geomagnetic repeat station network. South African J. Geology, 110, 187-192.)

\begin{abstract}
Within the Inkaba yeAfrica project, the number of geomagnetic repeat stations surveyed in southern Africa has been increased recently from eight to almost 40, through cooperation between Hermanus Magnetic Observatory (HMO), South Africa and GeoForschungsZentrum Potsdam (GFZ), Germany. Taking advantage of the extensive network of well-marked repeat stations formerly established by HMO in South Africa, Namibia and Botswana, and experience gained in using on-site variometers in former repeat station surveys carried out by GFZ, we could significantly improve the spatial data coverage of the area and also the quality of the results. Here we report on the survey and data processing methods, and discuss the accuracy of results, particularly with respect to the ability of the data to reflect the undisturbed internal magnetic field. Moreover, we briefly discuss how differences in the variometer recordings can reflect possible lateral changes in lithospheric conductivity.
\end{abstract}

\section{Introduction}

Since the start of systematic magnetic field recordings some 170 years ago, a continuous decrease of the Earth's magnetic dipole moment has been observed. The change in field strength is, however, not distributed evenly over the globe. One region where the most rapid decrease of field intensity is observed at the Earth's surface stretches across southern African and the South Atlantic Ocean. This more or less coincides with a region known as the South Atlantic Anomaly (SAA) where the field already is anomalously weak compared to other locations at the same latitude. Global geomagnetic field models show that the changes are associated with the growth of a patch of reverse magnetic flux, compared to the dominating dipole flux direction, at the core-mantle boundary (CMB) beneath southern Africa and the South Atlantic (Gubbins and Bloxham, 1985; Jackson et al., 2000, Wardinski and Holme, 2006). This growing area of reverse flux seems to play a significant role in the decrease of 
current dipole strength (Gubbins et al., 2006). Direct links between strong dipole decay and magnetic reversals have been shown by Gubbins (1987), and it has been suggested that we might be observing the early stages of such a reversal (Hulot et al., 2002; Olson, 2002). More details on the current state of knowledge about the geomagnetic field behaviour in this region are given by Mandea et al. (this issue).

Three geomagnetic observatories have continously recorded the geomagnetic field across the southern African continent over many years, i.e. the observatories at Hermanus (HER) and Hartebeesthook (HBK) in South Africa, and at Tsumeb (TSU) in Namibia. The observations over the past decades reveal that significant gradients in field change exist. The total intensity of the field over the past few years has decreased by about $30 \mathrm{nT} / \mathrm{yr}$ at HBK, $45 \mathrm{nT} / \mathrm{yr}$ at TSU and $55 \mathrm{nT} / \mathrm{yr}$ at HER. In addition, the angle of declination is increasing at HER and HBK (at both by about $8 \mathrm{~min} / \mathrm{yr}$ ), whilst it is decreasing at TSU at nearly the same rate. With distances of more than $1000 \mathrm{~km}$ between the three observatories, the data are not sufficiently dense to monitor in detail the spatio-temporal changes. Repeat station surveys are carried out at additional sites across southern Africa to improve this situation.

Geomagnetic observations include contributions from several sources: the main field originating in the Earth's core, influences from magnetised structures in the lithosphere, fields caused by current systems in ionosphere and magnetosphere, and counterparts induced in electrically conducting structures within the Earth by these time-varying fields. In order to study the magnetic core field a common assumption is that the field variations originating external to Earth average out over long time spans. A critical issue with repeat station surveys is to obtain representative values of the core field (e.g. comparable to annual means obtained from observatory recordings) from measurements distributed within less than 24 hours. The continuous recordings from the nearest observatory are generally used for reducing repeat station data to the desired internal field result. However, the geomagnetic variations can differ significantly between a repeat station and the nearest observatory. Common methods to minimize the influence of short-period variations include: 1) taking a large number of individual measurements and assume that external field influences will average out; 2) taking measurements during the night when magnetic activity at lower to mid-latitudes generally is low; or 3) temporally installing a portable variometer to monitor the external field changes during the observations (e.g. Newitt et al., 1996). Due to constraints on funding and available personnel, it is not always possible to carry out repeat station surveys in an optimal way, and some compromises have to be made. Here, we describe our efforts to optimise the southern African repeat station surveys with the available resources. Improvements to the results from the utilisation of a portable variometer are shown and reliable uncertainty estimates are derived for the different stations. Moreover, the variometer recordings can provide some basic information about changes in electrical conductivity between different sites and we mention some inferences which could be of interest for future surveys dedicated to lithospheric conductivity studies. The first regional geomagnetic field models based on our new magnetic field data are presented in an accompanying paper by Kotzé et al. (this issue).

\section{Repeat Station Network}

Geomagnetic repeat station surveys have been carried out for a long time by the Hermanus Magnetic Observatory (HMO). Since 1939, a total of 75 stations have been established in South Africa, Namibia, Botswana and Zimbabwe. A network of this size, however, could not be surveyed each year. A compromise had to be found between the need to monitor secular 
variation in detail on an annual to bi-annual basis and to keep a minimum number of stations to provide good spatial data coverage. In recent years, only 8 stations were surveyed annually (see Kotzé et al., this issue). A cooperation between HMO and GeoForschungsZentrum Potsdam (GFZ) within the framework of the Inkaba yeAfrica project allowed us to survey nearly 40 stations during 2005. At the time of writing, another cooperative survey in 2006 has just been finished. All stations are marked by sturdy pillars (Fig. 1), and the sites selected for the 2005 survey have all been chosen from the existing larger network. Figure 2 shows their locations.

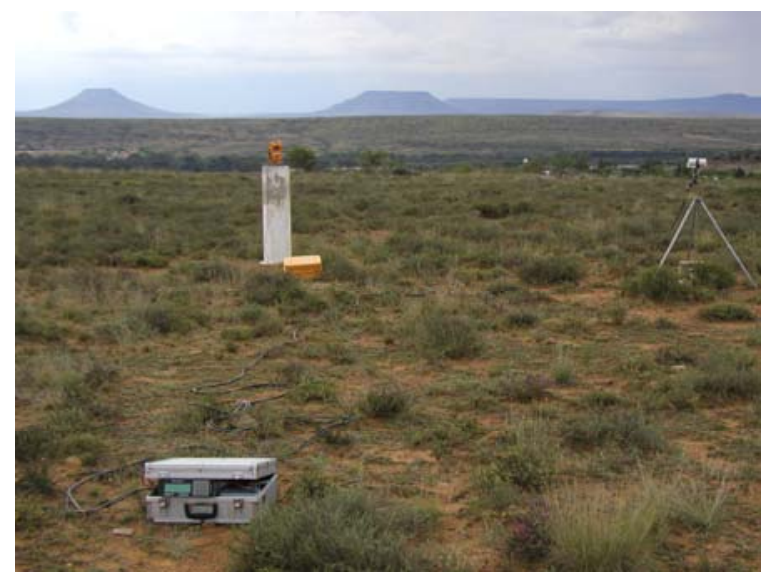

Figure 1: Example of a South African repeat station with a DI fluxgate theodolite on the station pillar and a GSM Overhauser magnetometer. The sturdy, non-magnetic beacon ensures exact re-location during subsequent surveys.

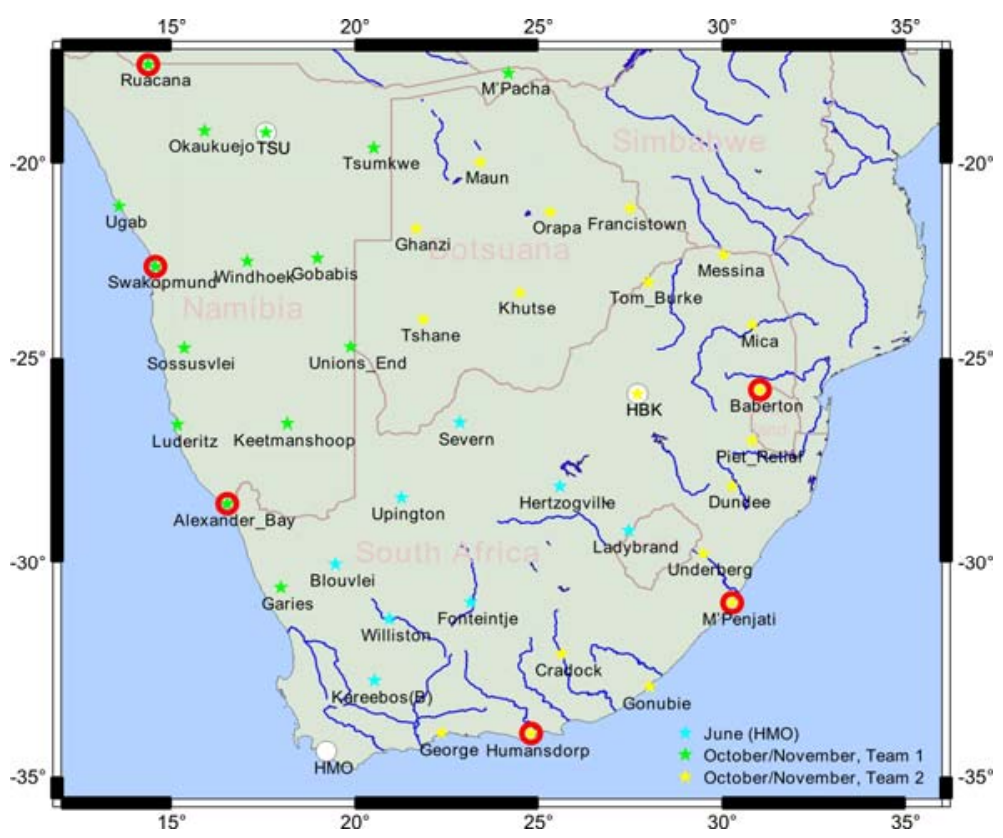

Figure 2: Southern African repeat station network in 2005. Red circles mark stations where measurements were impossible. 
Distances between stations are generally in the order of 200 to $400 \mathrm{~km}$. In 2005, seven stations were visited in June by a HMO team, while the bulk of stations was surveyed between 18 October and 16 November by two HMO/GFZ teams. The absolute instruments used were Zeiss 010B theodolites with Bartington fluxgate sensors for declination and inclination measurements and GSM19 Overhauser proton magnetometers for total intensity measurements. At many stations the pillars have the appropriate height and markers to set up and centre the theodolite directly on the pillar (as in Fig. 1). At some stations only lower pillars exist, in which case the instrument was set up above the centre mark using a special aluminium pillar extension or a tripod. A suspended LEMI008 variometer was used near each station to record the geomagnetic field variations.

Although many of the stations had not been visited for 7 years, most of them were in good condition and measurements were successfully completed. The validity of azimuth marks was checked by confirming the angles between at least three azimuth marks used and reported in previous surveys. Problems were encountered at 6 stations, where the measurement pillar or all well-determined azimuth marks had been destroyed or tampered with. Our tight schedule (see next section) did not allow for the establishment of new azimuth marks or alternative methods like sun observations. Measurements were carried out successfully at 34 stations.

\section{Survey methods}

The best method to obtain internal field results from repeat station surveys is to set up a portable variometer near the station. This ensures recording of all local field variations during the absolute measurements. The time interval should be long enough to include truly quiet night time values. However, this may require leaving the variometer in one place for several days. With limited resources this effort is clearly unfeasible. Another option is to set up a variometer at a central location while carrying out measurements at the surrounding stations. With distances of several hundred $\mathrm{km}$ between stations, however, such central stations often would still be more than $100 \mathrm{~km}$ away. This was considered a poor compromise for two reasons. First, we do not gain any information about the field variations directly at the chosen station. If strong local conductivity anomalies were present, then the differences in the variations (particularly of the vertical component) could be significant, even for distances of a few km only. Second, this method is still quite time-consuming, given the large driving distances. The chosen compromise was to set up the variometer at each station as long as possible for one night, and to take absolute measurements in the late evenings and early mornings. This reveals information on the external field variations directly at the station and their differences to those recorded at the observatories. If truly quiet magnetic conditions occur during night recordings good reduction results can be expected. Otherwise an average over several hours of recordings for the reduction can be used that will still lead to a better statistical average than using only a number of discrete absolute measurements. Further quantitative justification for this method is presented in the next section.

The variometer generally has to settle for a couple of hours after it is set up because it is strongly affected by temperature changes of the sensor. Moreover, it probably also needs to recover from mechanical strain induced on some components during transportation over rough roads. Once settled, however, both utilized suspended LEMI008 variometers have proven to be remarkably stable (as tested by setting up the instruments at the Niemegk and Hermanus observatories, where, over several days, the differences between LEMI008 and observatory 
variation recordings in general did not exceed $1 \mathrm{nT}$ ). Tests of heating and cooling both sensor and electronics unit separately showed that the LEMI008 is sensitive to sensor temperature changes in a way that cannot always be corrected for by applying a simple temperature coefficient. The sensor temperature therefore should be kept stable within a few degrees. The electronics temperature showed negligible influence within the test range of $30^{\circ} \mathrm{C}$. To keep the sensor temperature as stable as possible during operation, the variometer is buried in the ground and covered with an insulating lid, which ensured sensor temperature changes of less than $5^{\circ} \mathrm{C}$ between evening and morning absolute measurements at all stations. The variometer, a threecomponent fluxgate instrument, is oriented to record the field components declination $(\mathrm{D}$, in $\mathrm{nT})$, horizontal intensity $(\mathrm{H})$ and vertical intensity $(\mathrm{Z})$. By means of the evening and morning absolute measurements we obtain good baseline control for the variometer, confirming whether the instrument had settled by the time the first measurements were taken. This method has proven very efficient with the given station density and allowed us to follow a tight schedule as follows:

- drive to a station, arriving in the (early) afternoon

- set up the variometer

- wait 2 to 3 hours for the variometer to settle

- take 4 sets of absolute measurements in the evening

- take 4 sets of absolute measurements in the morning

- pack-up and drive to the next station, again arriving in the (early) afternoon.

In this manner, 8 individual sets of measurements were obtained at most stations. Time limitations or weather only occasionally limited the overall number to 5 to 7 sets, and in a couple of cases only 4 sets of morning measurements could be completed.

\section{Data processing, uncertainty estimates and results}

The data processing consists of two steps. First, one instantaneous absolute value per component is obtained from each set of measurements. This is achieved by the standard procedure used to obtain absolute measurements at geomagnetic observatories and which provides baseline values for the variometer. The amplitudes of geomagnetic field variations are much smaller than the core field strength, and variometers generally only record the variations while (arbitrary) constant field values of up to several $10000 \mathrm{nT}$ (depending on the component) are compensated for in the instrument. These constant field values are called baseline values, and adding them to the variations in each component provides the complete field vector over the entire time span of recordings.

In the second step the undisturbed internal field has to be determined. This is generally desired for a common time, most conveniently at mid-year, to be comparable to the standard observatory annual means. Even with a local variometer, long-term observatory recordings are necessary for this data reduction step. The annual mean at a repeat station, $\mathbf{E}$, is obtained by

$$
\mathbf{E}=\mathbf{E}_{0}+\left(\mathbf{E}(t)-\mathbf{E}_{0}(t)\right)
$$

Here, $\mathbf{E}_{\mathbf{0}}$ is the observatory annual mean (or internal field value at any other desired time), while $\left(\mathbf{E}(t)-\mathbf{E}_{\mathbf{0}}(t)\right)$ is the difference between the measurements at the repeat station at time $t$ and the value recorded at the observatory at the same time. The underlying assumption is that all 
time variations, external, induced and secular variation, are the same at both locations. Using the local variometer, i.e. the average difference $\left(\mathbf{E}(t)-\mathbf{E}_{0}(t)\right)$ over one full night, minimizes the influence of short-period variations. It is possible to apply a linear correction for differences in secular variation at the observatory $\left(\mathbf{S V}_{\mathbf{0}}\right)$ and the repeat station $(\mathbf{S V})$ as

$$
\mathbf{E}=\mathbf{E}_{\mathbf{0}}+\left(\mathbf{E}(t)-\mathbf{E}_{\mathbf{0}}(t)\right)+\left(\mathbf{S V}-\mathbf{S V}_{\mathbf{0}}\right) \Delta T
$$

where $\Delta T$ is the time difference between the reduction epoch (middle of the year for annual means) and time $t$ of the measurement (Newitt et al., 1996). This correction includes some circularity because in essence $\mathbf{S V}$ is the quantity to be determined by repeat station measurements and can only be estimated from a previous time-series of measurements at the respective station, derived from a global or regional field model, or derived from interpolation between the secular variation at two or more surrounding observatories.

Below we discuss the various sources of error in our method of using repeat station measurements and data reduction, in order to provide uncertainty estimates for the final results. Possible errors to be considered are instrumental or measurement errors, positioning errors and errors in reducing data to undisturbed internal field values.

Measurement errors and instrumental errors are generally the same as at geomagnetic observatories. For the DI fluxgate theodolite, they might be slightly larger due to influence by weather conditions or relative stability related to mounting the instrument on a tripod. We obtain a good estimate of such errors from the scatter of the up to eight individual baseline values at each station. The maximum deviation from the mean in two to four measurements within a couple of hours in the evening or morning, respectively, is seldom larger than $0.3 \mathrm{~min}$ (equivalent to about $1 \mathrm{nT}$ in that region) in declination and $0.7 \mathrm{nT}$ in horizontal and vertical intensity. At most stations, the mean baseline difference between morning and evening measurements is also in the order of $1 \mathrm{nT}$, and in these cases the maximum deviation from the mean in all up to eight measurements together is mostly less than $1.5 \mathrm{nT}$. However, there are a few cases where significant differences of up to $10 \mathrm{nT}$ occur between the evening and morning measurements, often only in declination. The first possible, but unlikely explanation for this is that they are positioning errors (see below). Instead, we suppose that small differences mainly reflect temperature variations of the variometer recordings. However, in the cases with the most severe differences, a drift is present in the variometer recordings that we do not yet understand. Fig. 3 shows such an example. Here, the recordings of all three observatories show a similar trend in $\mathrm{D}$, while the variometer recording is significantly different. The baseline differences between evening and morning are $0.6 \mathrm{nT}$ in $\mathrm{H}$ and $1.6 \mathrm{nT}$ in $\mathrm{Z}$, but $-27.8 \mathrm{nT}$ in $\mathrm{D}$. The bottom panel of the figure shows that this large baseline difference in $\mathrm{D}$ is in the same order as the change in differences between each of the observatories and the variometer recordings from evening to next morning. This kind of instrumental drift problem is under investigation using variometer recordings taken during the recent 2006 survey and more long-term tests at the observatories.

Positioning errors can mostly be considered as negligible for several reasons. The stations and pillar centres are precisely marked, and at most of the stations the local field gradients are low. Moreover, the observation of at least three azimuth marks at each station ensured the exact centring of the instrument. Low scatter of individual results at most stations described above confirms this. 


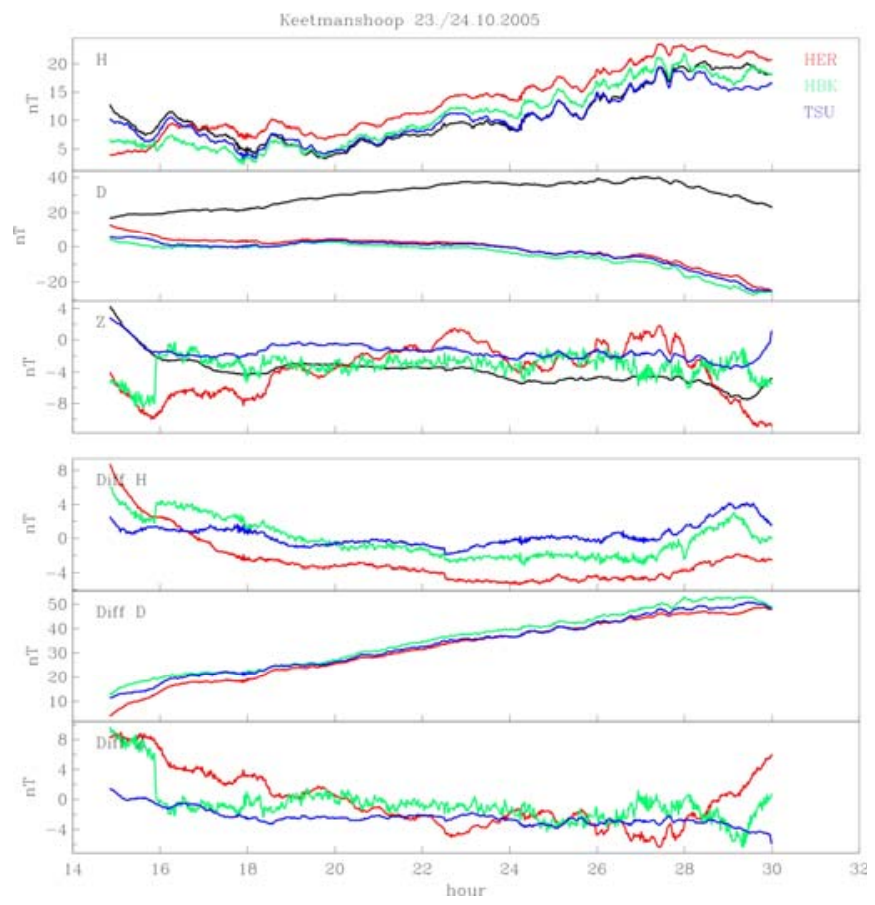

Figure 3: Variations of horizontal intensity $(H)$, declination (D) and vertical intensity $(Z)$ at repeat station Keetmanshoop (black line) and the three southern African observatories (upper panel). In the

lower panel, the differences between recordings at Keetmanshoop and the three observatories, respectively, are shown. The time starts with hour UT on the first day. Note the different vertical scales here and in subsequent figures.

Reduction errors can be a significant source of uncertainty, but are difficult to assess. By means of the variometer recordings at each station we can eliminate reduction errors due to short-period differences in field variation, as demonstrated in Fig. 4. This figure shows the recordings during one night at repeat station Gonubie, along the coast about halfway between HER and HBK, and the recordings at the three observatories. In this example the baseline differences between the averages of 4 evening and 4 morning absolute measurements are $0.1 \mathrm{nT}$ in $\mathrm{D}, 0.7 \mathrm{nT}$ in $\mathrm{H}$ and $-1.3 \mathrm{nT}$ in $\mathrm{Z}$. The differences between the repeat station and observatory recordings can be significant. During the night, differences with the observatories' recordings are nearly constant (in D and Z even for TSU, which is very far away), but during the times of absolute measurements up to the early evening, differences vary significantly. Data reduction with only observatory recordings would show much higher scatter in individual measurement results and less well-determined mean values.

Employing variometer measurements takes care of short-period variations, but how well do the night-time values at a specific day reflect the undisturbed internal field and how accurately can we reduce the repeat station data to a common epoch? Even in the absence of short-period external variations apparently quiet night time field recordings can be offset from the internal field level. To get an idea about the order of magnitude of uncertainties caused by such displaced night time levels and by differing secular variation in our study area we investigated differences in one year's data between the three observatories, i.e. Hermanus (HER), Hartebeesthoek (HBK) and Tsumeb (TSU). 


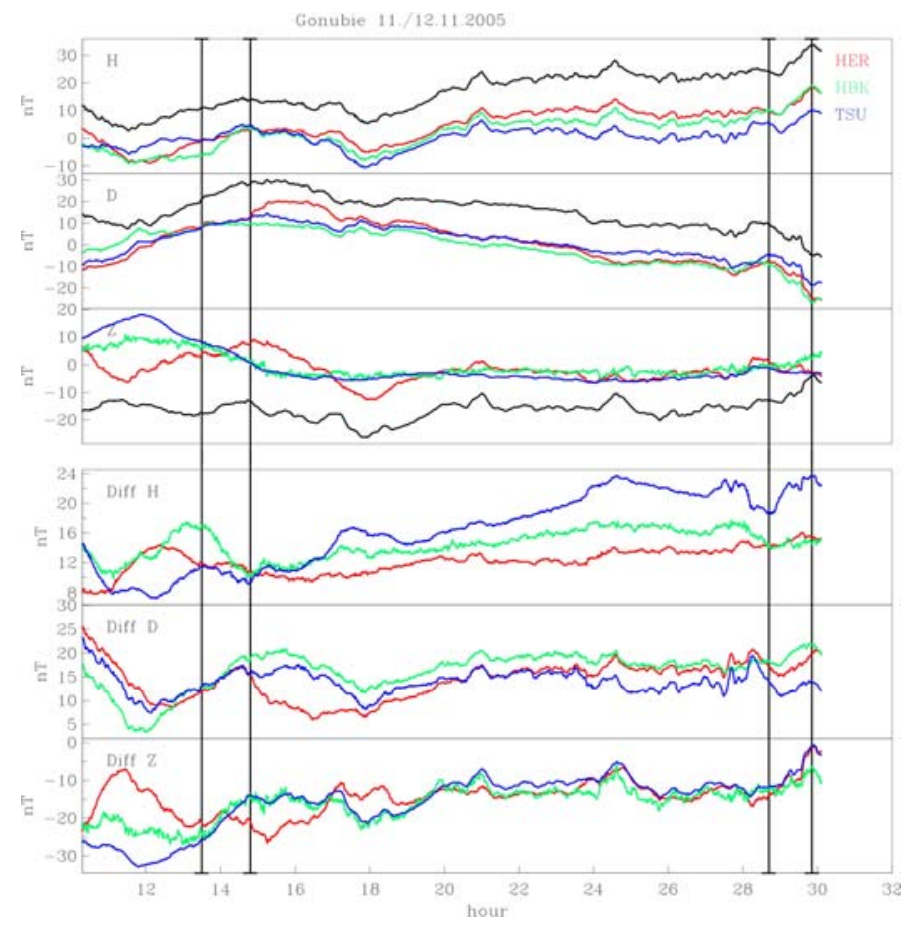

Figure 4: Variations and differences (as in Fig. 3) for repeat station Gonubie. Time intervals of absolute measurements at the station are marked by vertical bars.

We studied the differences between HER-HBK, HBK-TSU and TSU-HER, after subtraction of the annual mean values for the year 2001. Assuming that the annual means reflect the undisturbed internal field in the middle of the year, any non-zero difference reflects the error one would make when reducing data measured at one observatory with the recordings from the other. During the time of our field measurements these differences reach $\pm 30 \mathrm{nT}$ in $\mathrm{X}$ and $\mathrm{Y}$ and up to $\pm 55 \mathrm{nT}$ in $\mathrm{Z}$. First, we checked the agreement between the difference of the standard annual means, averaged over all minutes of the day, and all days of the year, and both the quiet night time annual means between 0:00 and 4:00 am, $K p<2$, and all nights annual means between $6: 00 \mathrm{pm}$ and 6:00 am. $K p$ is a global geomagnetic activity index ranging from 0 to 9. (http://www.gfz-potsdam.de/pb2/pb23/GeoMag/niemegk/kp_index/index.html). Quiet night annual means and all night annual means agree within $1 \mathrm{nT}$, except for the $\mathrm{Z}$ component, where the difference for HER is $2 \mathrm{nT}$. An average taken over a large number of night-time values obviously reflects the internal field very well. However, the night time annual mean differences deviate from the standard annual mean differences by up to $3 \mathrm{nT}$ in $\mathrm{D}, 6 \mathrm{nT}$ in $\mathrm{H}$ and $9 \mathrm{nT}$ in $\mathrm{Z}$, confirming the known fact that all day annual means are not the best representation of the undisturbed internal field contribution.

The question we really want to answer, however, is how well the average over only one arbitrary night reflects the internal field and can be reduced with confidence, therefore, to an "annual mean". We also have to consider differences in secular variation and in displacement from the quiet night time level. Fig. 5 gives a flavour of these influences. This figure, and Table 1, show that secular variation within one year cannot be neglected in repeat station data reduction in the southern African region. Within only one month the observatory differences 
increase or decrease systematically by up to $5 \mathrm{nT}$ due to differing secular variation. Although for the reduction of repeat station data the influence will be at most half of these values if the nearest observatory is chosen for data reduction, secular variation should clearly be considered if data are reduced over more than a month.
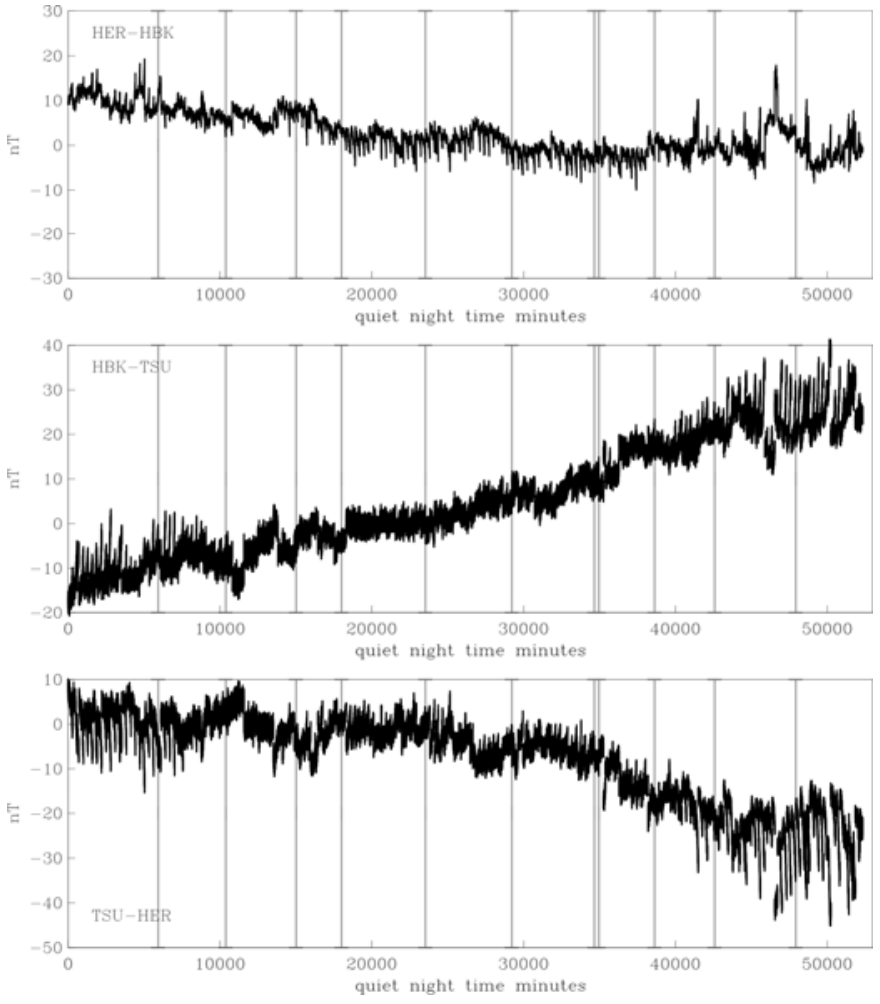

Figure 5: Differences in quiet night time values of the $\mathrm{H}$ component at the three observatories in southern Africa. The time interval is January to December 2001, but data are unevenly spaced due to the uneven distribution of quiet night time data, defined here as all one-minute values between 0:00 and 4:00am when $K p<2$. Gray vertical bars divide the time-scale into months.

Table 1: Changes in internal field differences between January and December 2001 in nT / approximate values per month in $\mathrm{nT}$.

\begin{tabular}{lrrr} 
& HER-HBK & HBK-TSU & TSU-HER \\
\hline $\mathrm{D}$ & $+17.4 /+1.5$ & $-63.1 /-5.3$ & $+45.7 /+3.8$ \\
$\mathrm{H}$ & $-11.5 /-1.0$ & $+36.7 /+3.0$ & $-25.1 /-2.1$ \\
$\mathrm{Z}$ & $+21.6 /+1.8$ & $-2.7 /-0.2$ & $-18.9 /-1.6$ \\
\hline
\end{tabular}

To estimate average displacements of arbitrary one-night averages from the undisturbed internal field, we finally compared differences of individual one-night averages $6: 00 \mathrm{pm}$ to 6:00am) to those of monthly quiet night time averages. The one-night averages mostly lie within $\pm 2 \mathrm{nT}$ of the monthly mean, both for quiet and moderately disturbed nights. A rigorous 
analysis of possible systematic correlations between $K p$ and displacement of quiet night time level is beyond the scope of this work. We are interested in some realistic uncertainty estimates for our data and for that purpose this analysis suggests that one-night averages with $K p$ values up to about 4 generally reflect the internal field reasonably well.

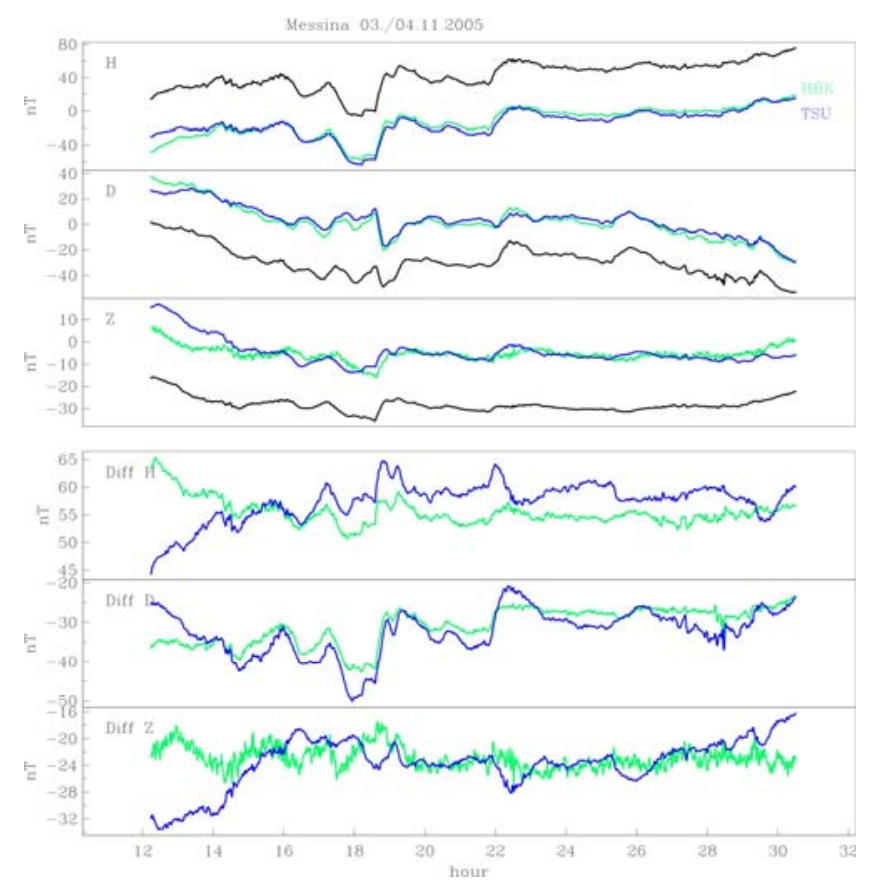

Figure 6: Variations and differences as in Fig. 3 for repeat station Messina and two of the observatories. Variations in $\mathrm{Z}$ are more homogeneous at the three locations than in $\mathrm{H}$ and $\mathrm{D}$.

Summarising the considerations on uncertainty estimates, we conclude that with the instruments and methods used in this study, even under moderately disturbed field conditions we could, in general, achieve a measurement accuracy within about $\pm \ln T$, slightly lower in D and slightly higher in $\mathrm{H}$ and $\mathrm{Z}$. The larger uncertainty lies in the determination of the common undisturbed internal field level. Given the favourable, mainly quiet conditions during the 2005 survey, we should, in general, be able to achieve an accuracy of $\pm 2 \mathrm{nT}$ in all components. For stations which are surveyed annually to bi-annually, secular variation can be taken into account reasonably well by equation 2 and final results reduced to a common epoch can be expected to have average uncertainties of less than $\pm 3 n T$.

\section{Inferences about lithospheric conductivity}

Differences in the recorded short-period variations, particularly in the vertical component, where the induction influence is most pronounced, can provide information about lateral changes in the lithospheric electrical conductivity. For a detailed investigation and the inference of conductivity models, more specific geomagnetic depth sounding or magnetotelluric experiments are necessary, but we might draw some rough conclusions about lithospheric conductivity changes by comparing the recordings from different stations. For this purpose, however, it is a disadvantage that conditions were magnetically rather quiet during the survey, 
since differences in induced fields due to variations in conductivity are most pronounced during periods of strong magnetic activity.

Data from Botswana, northern South Africa and eastern Namibia seem to suggest that induction does not play a significant role in magnetic variations in these regions and consequently conductivity could be rather uniform there. Several of these recordings give similar results. For example, variations in $\mathrm{Z}$ do not differ much between the repeat station at Messina and both the observatories HBK and TSU (Fig 6). This example is from one of few stations where stronger variations (and differences) in $\mathrm{H}$ and $\mathrm{D}$ are observed. However, for several locations the recordings of all three observatories and the repeat station appear very similar simply because only small variations occurred during the time that the variometer was operational. Future variometer recordings at these locations, under different magnetic conditions, are necessary to decide how homogeneous the variations at these stations and the nearest observatory really are.

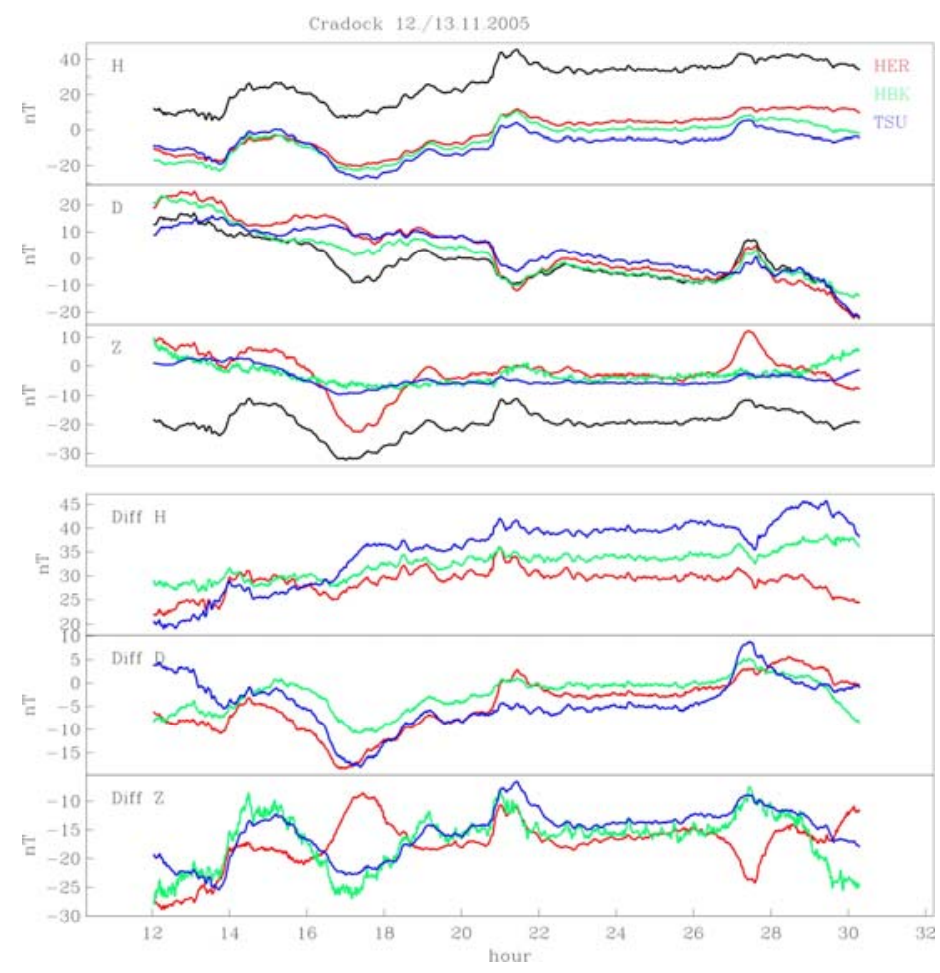

Figure 7: Variations and differences as in Fig. 3 for repeat station Cradock. Significantly different variations in $\mathrm{Z}$ at $\mathrm{HER}$ are due to the ocean induction effect.

Strong effects on the vertical component variation occur near the coasts due to the highly conductive sea water, a phenomenon known as ocean effect (Fainberg, 1980). This effect can be seen at the repeat stations along the coasts, and also in the Hermanus Observatory recordings. Figure Error! Reference source not found. shows that the effect is strong and impedes conclusions about lithospheric conductivity at coastal stations and all the southern stations for which Hermanus is the nearest, reference observatory. This is somewhat unfortunate, as with our sparse data it is impossible to discriminate between influences of the ocean and of the major structure known as the Southern Cape Conductive Belt, stretching east- 
west over the continent slightly south of $32^{\circ} \mathrm{S}$. This structure was originally described by Gough et al. (1973), and de Beer et al. (1982) and is also a topic of study within the Inkaba yeAfrica project (e.g. Weckmann et al., 2007, and this volume). In the horizontal component the variations at the Cradock repeat station, for example, are most similar to those at the nearest observatory (HER). In Z, however, variations at HER are very different and much stronger than at the other two observatories, whereas the variations at Cradock repeat station fall somewhere in between.

Figure 8 shows an example that truly hints at differences in lithospheric conductivity, in this case between TSU and Windhoek, about $400 \mathrm{~km}$ south of the observatory. Opposite signs in Z variations at certain frequencies indicate a conductivity contrast, with the centre of the conductive structure lying between the stations. A systematic search for the existence or absence of such effects is not straightforward with our current data. Recordings under a broader range of geomagnetic activity at each station, or under comparable magnetic activity at the different stations, respectively, are necessary for a rigorous assessment of the influence of induction.

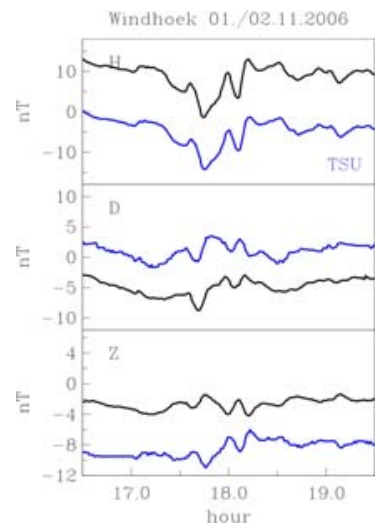

Figure 8: Variations at Windhoek and TSU show opposite sign in Z for certain frequencies.

\section{Conclusions and outlook}

In 2005, the repeat station survey the network of Southern Africa was enlarged from the 8 stations surveyed in 2003 and 2004 to almost 40 stations, some of them last surveyed in 1998. Successful measurements were carried out at 34 stations. We have improved the measurement method by using a portable variometer at each station for recording the geomagnetic variations during one night. Uncertainties from differences in short-period field variations between a repeat station and the nearest observatory are thus eliminated. From an analysis of scatter in up to eight individual field measurements at each station, and through a study of night time field displacement from the undisturbed internal level, we estimate the uncertainties of the final results to be around $\pm 2 \mathrm{nT}$ in $\mathrm{H}$ and $\mathrm{Z}$ and 1 min in $\mathrm{D}$.

The variometer recordings provide additional information about lithospheric electrical conductivity conditions at the repeat station locations. With different levels of geomagnetic activity at the different locations, a systematic assessment is currently not possible. Variometer recordings from future repeat station surveys of the southern African network, however, will 
provide data from a broader range of magnetic conditions at each station and enable more conclusive investigations of lateral changes.

The results of the 2005 repeat station survey have been used to develop a new regional reference field and secular variation model (Kotzé et al., this issue) and will be used further to study the processes leading to the exceptional field gradients and intensity decrease in that area (Mandea et al., this issue). For that purpose, however, it is first necessary to obtain current secular variation results from all the surveyed stations. 26 of these stations were last visited 7 years ago. Due to the temporal variability and nonlinearity of secular variation an average over 7 years cannot be regarded as high-quality secular variation result. Further data meanwhile have become available from another joint HMO-GFZ survey of the 40 stations. This was completed in December 2006 and data processing was nearly finished at the time of writing.

\section{Acknowledgements}

We wish to thank the Geological Survey of Namibia, Ministry of Mines and Energy, as well as the Geological Survey of Botswana for continuous support in carrying out repeat station measurements in these countries. We particularly acknowledge the participation of Tiyapo Ngwisanyi in the 2005 survey in Botswana. The constructive comments of an anonymous referee and editor Maarten de Wit helped to improve the original manuscript. This is Inkaba yeAfrica contribution 15.

\section{References}

J. de Beer, J. van Zijl, and D. Gough (1982). The Southern Cape Conductive Belt (South Africa): Its composition, origin and tectonic significance. Tectonophysics, 83, 205225.

D. Gough, J. de Beer, and J. van Zijl (1973). A magnetometer array study in southern africa. Geophysical Journal of the Royal Astronomical Society, 34, 421-433.

D. Gubbins (1987). Mechanism for geomagnetic polarity reversals. Nature, 326, 167-169.

D. Gubbins and J. Bloxham (1985). Geomagnetic field ananlysis - III. Magnetic fields on the core-mantle boundary. Geophysical Journal of the Royal Astronomical Society. 80, 695-713.

D. Gubbins, A.L. Jones, and C.C. Finlay (2006). Fall in Earth's magnetic field is erratic. Science, 312, 900-902.

E. B. Fainberg (1980), Electromagnetic induction in the world ocean, Geophysical Surveys, 4,157-171, 1980

G. Hulot, C. Eymin, B. Langlais, M. Mandea, and N. Olsen (2002). Small-scale structure of the geodynamo inferred from Oersted and Magsat satellite data. Nature, 416, 620 623.

A. Jackson, A. R. T. Jonkers, and M. R. Walker (2000). Four centuries of geomagnetic secular variation from historical records. Philosophical Transactions of the Royal Society, London, Series A, 358, 957-990.

P. Kotzé, M. Mandea, and M. Korte (2007). Modelling the southern African geomagnetic field secular variation using ground survey data for 2005. South African Journal of Geology, this issue. 
M. Mandea, M. Korte, D. Mozzoni, and P. Kotzé (2007). The magnetic field changing over the Southern African continent - a unique behaviour. South African Journal of Geology., this issue.

L. R. Newitt, C. E. Barton, and J. Bitterly (1996). Guide for magnetic repeat station surveys. International Association of Geomagnetism and Aeronomy.

P. Olson (2002). The disappearing dipole. Nature, 416, 591-594.

I. Wardinski and R. Holme (2006). A time-dependent model of the earth's magnetic field and its secular variation for the period 1980 to 2000. Journal of Geophysical Research, 111, B12101, doi:10.1029/2006GB004401.

U. Weckmann, O. Ritter, A. Jung, T. Branch, and M. De Wit (2007). Magnetotelluric measurements across the beattie magnetic anomaly and the Southern Cape Conductive Belt, South Africa. Journal of Geophysical Research, 112, B05416, doi:10.1029/2005JB003975. 